\title{
DISTORTION OF 16MnCr5 STEEL PARTS DURING LOW-PRESSURE CARBURIZING
}

\author{
Konrad Dybowski ${ }^{1}$, Rafał Niewiedzielski ${ }^{1}$ \\ 1 Institute of Materials Science and Engineering, Lodz University of Technology, Stefanowskiego 1/15, 90-924 \\ Łódź, Poland, e-mail: konrad.dybowski@p.lodz.pl
}

Received: 2016.12 .15

Accepted: 2017.02.01

Published: 2017.03.01

\begin{abstract}
One of the many advantages of low pressure carburizing (LPC) is that it can be combined with high-pressure gas quenching. This makes it possible to achieve workpieces with pure metallic surfaces, less distortion hardening, and, above all, it allows a more reliable and repeatable treatment than conventional oil quenching. This article presents a study of the distortion rate of workpieces carburized at low pressure then quenched in nitrogen at 1.4 MPa. By comparing the distortion which takes place during the carburizing stage only and the carburizing combined with post-carburizing heat treatment it will be possible to assess the distortion rate and its causes at the different stages of the heat treatment process.
\end{abstract}

Keywords: thermo-chemical treatment, low pressure carburizing, distortion, gas quenching.

\section{INTRODUCTION}

Low pressure carburizing has numerous advantages over conventional carburizing methods, such as its greater speed (by applying higher treatment temperatures and atmospheres with a considerably higher carbon potential) and the absence of internal oxidation. Additionally, this method also allows the use of gases as cooling agents $[5 \div 8,11 \div 13]$.

During traditional post-carburizing heat treatment, the most commonly used cooling agents are quenching oil, and on occasion emulsions and polymers with specific cooling properties. The major drawbacks of using oil are the fumes produced during quenching and the necessity to wash and rinse the treated parts between quenching and tempering, which constitutes a serious ecological problem. Oil quenching also poses a fire hazard $[3,4,10]$.

For these reasons, in modern LPC furnace systems, carburized parts are cooled using high pressure gas. Gas cooling agents - based mainly on nitrogen, helium, hydrogen or their compos- ite - do not pollute the environment, ensure the treated steel parts have a clean, metallic surface, and do not require any additional treatment after quenching. After oil quenching, however, it is necessary to wash the parts, most commonly in alkaline baths, then to rinse and dry them. This in turn means it is necessary to neutralize drains and use oil residue separators. Additionally, systems with washing appliances occupy more space, whereas compact vacuum systems can be installed in technological lines, thus minimizing inter-operational transport $[1,3,9,10,16]$.

The efficiency of gas quenching carburized batches largely depends on their type (cooling capacity), the pressure applied, and the speed of the gas streams flowing over the surface details. Helium and hydrogen have the greatest quenching capacities of the gases used. However, despite their higher heat transfer coefficient, particularly that of hydrogen, neither gas is likely to be applied as a modern cooling agent in heat treatment. Helium is extremely expensive and requires costly and extensive recycling systems; while hydrogen, due to its high risk of explosion, poses a logistics 
problem - although attempts are being made to eliminate this, for example by storing hydrogen in hydrides $[2,9,16]$.

Currently, the most commonly used quenching agent in LPC is nitrogen. Vacuum furnace chambers used for carburizing are adapted to work under a pressure of $2.5 \mathrm{MPa}$. These are single or doublechamber furnaces, or modular line systems. In single-chamber furnaces, the same chamber is used for heating and quenching batches. Quenching is carried out by circulating gas through a system of nozzles in the closed working area of the furnace in which the batch is directed. Double-chamber furnaces have a separate heat chamber and cooling chamber in which the batch is quenched. The separate cooling chamber provides a higher quenching intensity. In mass production, where the treatment process requires a higher intensity due to the number of workpieces, a modular line system is applied, in which one quenching chamber serves several vacuum carburizing chambers. There are two ways of implementing such a system: as continuous multi-chamber furnaces, or a nested multichamber unit structure $[9,16]$.

The use of gas quenching at increased pressure not only brings benefits to the environment, but also results in reduced distortion hardening and, above all, a more uniform hardening process. This makes it easier to predict the required amount of surplus finishing treatment, and in the case of workpieces with lower accuracy demands (items with less complicated geometries), allows for a 'one-off' treatment $[1,3,9,10,15,16]$.

The aim of the research carried out in this article was to estimate the distortion volume of $16 \mathrm{MnCr} 5$ steel workpieces that takes place at the low pressure carburizing stage and results from the high pressure gas quenching (nitrogen) process. It will thus be possible to evaluate the extent of distortion caused by diffusion saturation and gas quenching.

\section{MATERIAL AND METHODS}

Gear wheels made of $16 \mathrm{MnCr} 5$ steel (chemical composition Table 1), of module $\mathrm{m}=5$ and the number of teeth $=30$ were vacuum carburized (Fig. 1). Carburizing was done in a onechamber furnace with high-pressure nitrogen cooling manufactured by Seco/Warwick S.A. The dimensions of the furnace heating chamber: $600 \times 600 \times 900 \mathrm{~mm}$. Each gear wheel was posi- tioned vertically in the middle area of the furnace chamber on a special device, which guaranteed the well-defined and repeatable deployment during carburizing and cooling. The first two teeth of each wheel were marked permanently on their side surfaces to ensure the repeatable conditions of the experiment (as shown in Fig. 1). Gear wheels, before the carburizing process, were annealed in vacuum at $860{ }^{\circ} \mathrm{C}$ for 3 hours. The carburizing atmosphere consisted of a mixture of acetylene - ethylene - hydrogen. Carburization was done in the FineCarb ${ }^{\circledR}$ technology [14]. The parameters of the carburized layer were designed: surface carbon concentration $=0.8 \%{ }_{\text {wt }}$, effective case depth $=1.0 \mathrm{~mm}$ (for criterion $=0.4 \%{ }_{\text {wt. }} \mathrm{C}$ ). In order to achieve the desired carbon concentration profile, the duration of the boost/diffusion process segments was selected based on the simulation made using the SimVaCPlus ${ }^{\circledR}$ program.

The vacuum carburizing process stages are described below:

- pumping up to pressure $10 \mathrm{~Pa}$,

- heating up to temperature $1050{ }^{\circ} \mathrm{C}$ with ramp $10^{\circ} \mathrm{C} / \mathrm{min}$.,

- soaking for $20 \mathrm{~min}$. at $1050{ }^{\circ} \mathrm{C}$,

- vacuum carburizing at $1050{ }^{\circ} \mathrm{C}$, at pressure $300 \div 800 \mathrm{~Pa}$, boost/diffusion time [min.]: 4:00/10:00, 2:00/17:00, 2:00/34:00, 2:00/31:00,

Table 1. Chemical composition $16 \mathrm{MnCr} 5$ steel used to research (\%wt.)

\begin{tabular}{|c|c|c|c|c|c|c|c|}
\hline $\mathrm{C}$ & $\mathrm{Mn}$ & $\mathrm{Cr}$ & $\mathrm{Ni}$ & $\mathrm{Cu}$ & $\mathrm{Si}$ & $\mathrm{P}$ & $\mathrm{S}$ \\
\hline \multicolumn{8}{|c|}{$[\%$ wt. $]$} \\
\hline 0,16 & 1,21 & 0,84 & 0,02 & 0,03 & 0,20 & 0,03 & 0,03 \\
\hline
\end{tabular}

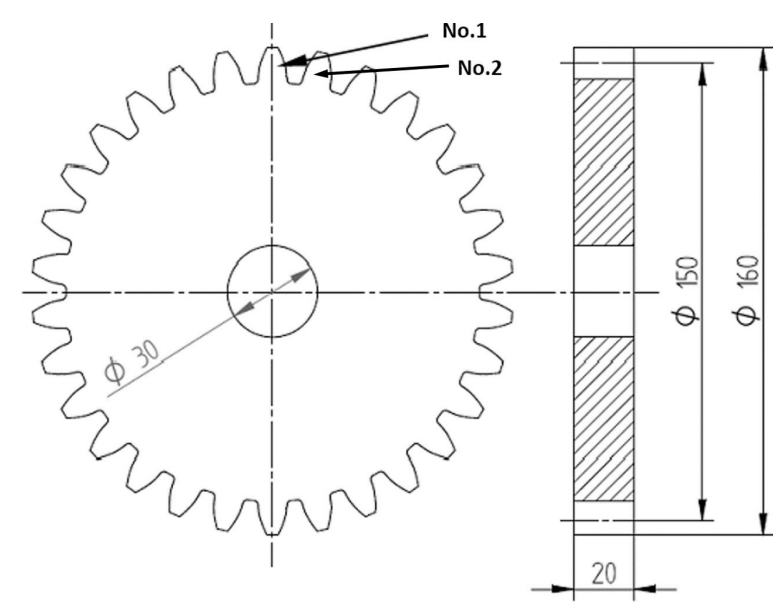

Fig. 1. Gearwheel used in researches, module $=5$, number of teeth $=30$ [3] 
- precooling to temperature $860^{\circ} \mathrm{C}$ and soaking for $20 \mathrm{~min}$,

- gas quenching (nitrogen) to $50^{\circ} \mathrm{C}$ at a pressure of 1.4 MPa or slow cooling of the furnace.

\section{RESULTS AND DISCUSSION}

After carburizing and gas quenching, on the outer layer a martensite structure with residual austenite could be observed (Fig. 2), while in the core of steel, a mixture of bainite with a small quantity of ferrite (Fig. 3). The surface layer carbon profile obtained in the vacuum carburizing processes are shown in Figure 4. The carbon concentration in a layer was measured with a glow discharge optical emission spectrometer - LECO GDS850A. As a result of LPC, the concentration of carbon on the outer layer of the treated steel was as predicted. Figure 5 shows the distribution of micro-hardness as a function of the distance from the surface for $16 \mathrm{MnCr} 5$ steel obtained by vacuum carburizing and gas quenching. The hardness of the outer layer was normal, increasing incrementally from the core to the outer layer, with a core value of approximately $440 \mathrm{HV}$ and a surface measurement of approximately $800 \mathrm{HV}$. When there was a residual amount of austenite, the hardness on the outer layer was slightly lower (approx. 750HV).

Measurements of the gear wheels used in the experiment were performed in order to determine the effect of thermal treatment on deformations. Radial run-out was measured on the pitch diameter before and after carburizing

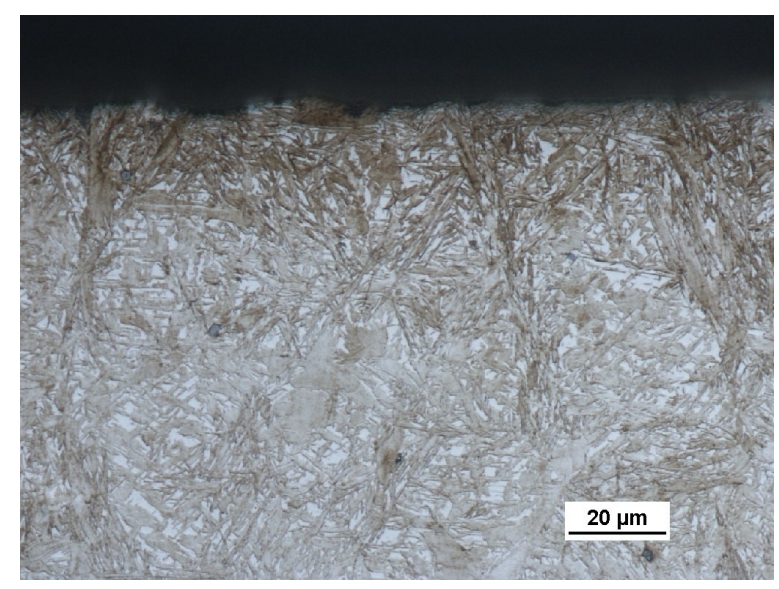

Fig. 2. Microstructure of the surface layer of $16 \mathrm{MnCr} 5$ steel after low pressure carburizing and gas quenching

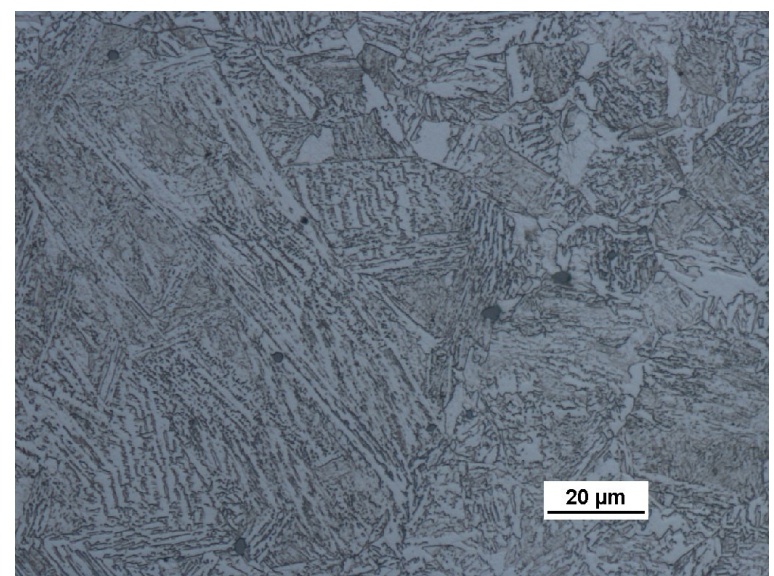

Fig. 3. Core microstructure of $16 \mathrm{MnCr} 5$ steel after low pressure carburizing and gas quenching

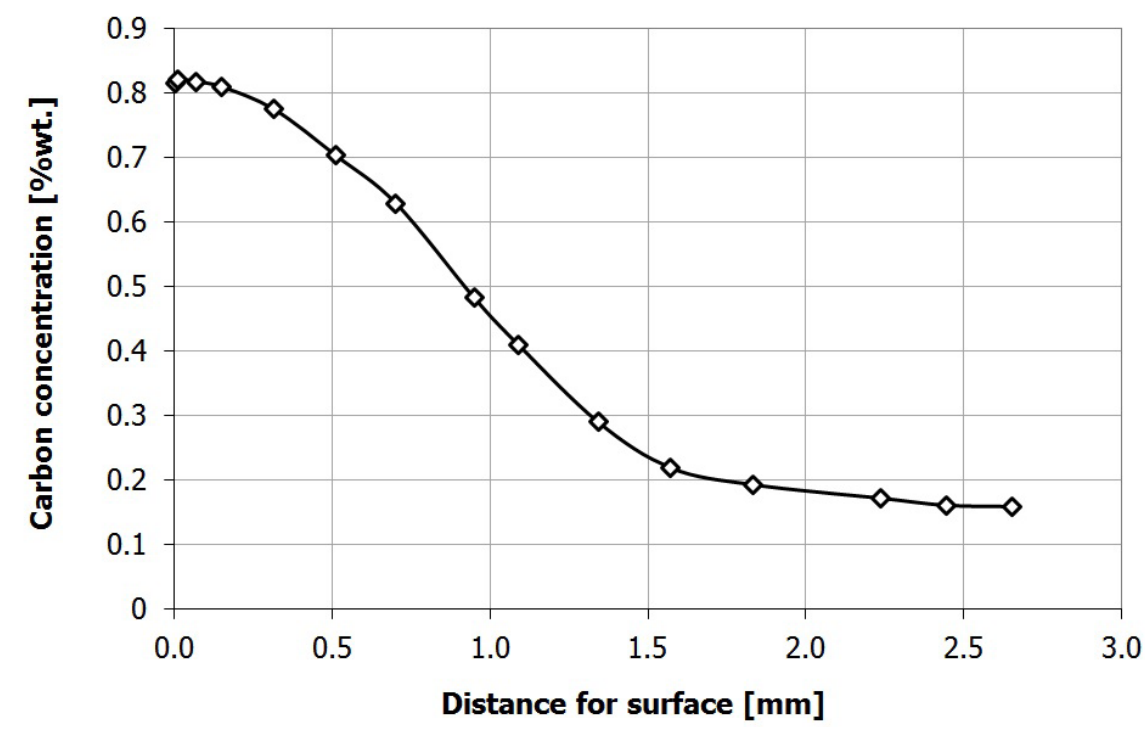

Fig. 4. The carbon profiles after low pressure carburizing processes of $16 \mathrm{MnCr} 5$ steel 


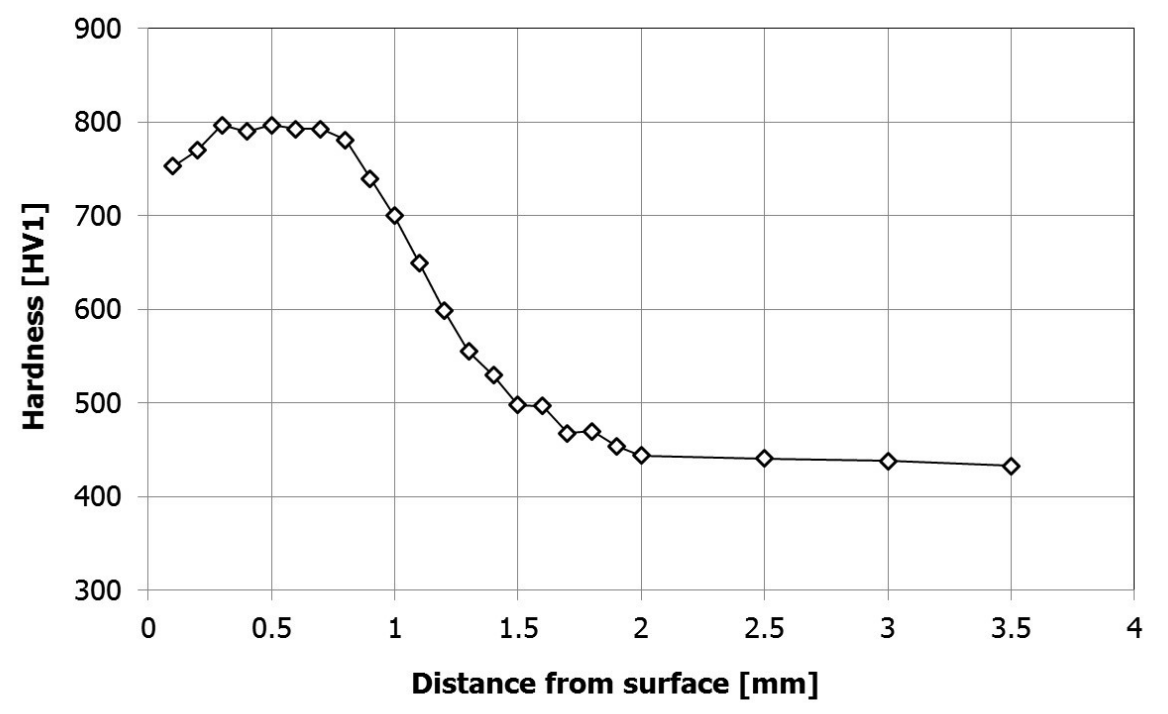

Fig. 5. Microhardness profile of $16 \mathrm{MnCr} 5$ steel after low pressure carburizing with hardening

with or without gas quenching. Radial run-out was measured with an accuracy of $\pm 0,001 \mathrm{~mm}$ by gearwheel measurement device manufactured by Carl Zeiss Jena. The measurements were performed for each gear wheel by determination of the radius from the rotation axis to the pitch diameter.

The measurement results are shown in the diagrams presented in Fig. 6 and Fig. 7. The mean de- formation is $8 \pm 6 \mu \mathrm{m}$ after gas quenching and $7 \pm 6$ $\mu \mathrm{m}$ after slow cooling of the furnace. Next measurement was made of the tooth thickness of each of the gear wheels on three different heights: on the head tooth (h1), on the pitch diameter (h2) and on the foot of the tooth (h3). The measuring position from the top of a tooth was: $1.5 \mathrm{~mm}(\mathrm{~h} 1), 5.0 \mathrm{~mm}(\mathrm{~h} 2)$ and $9.5 \mathrm{~mm}$ (h3), as shown in Fig. 8. The results of these study are presented in figure 9 and 10 . The

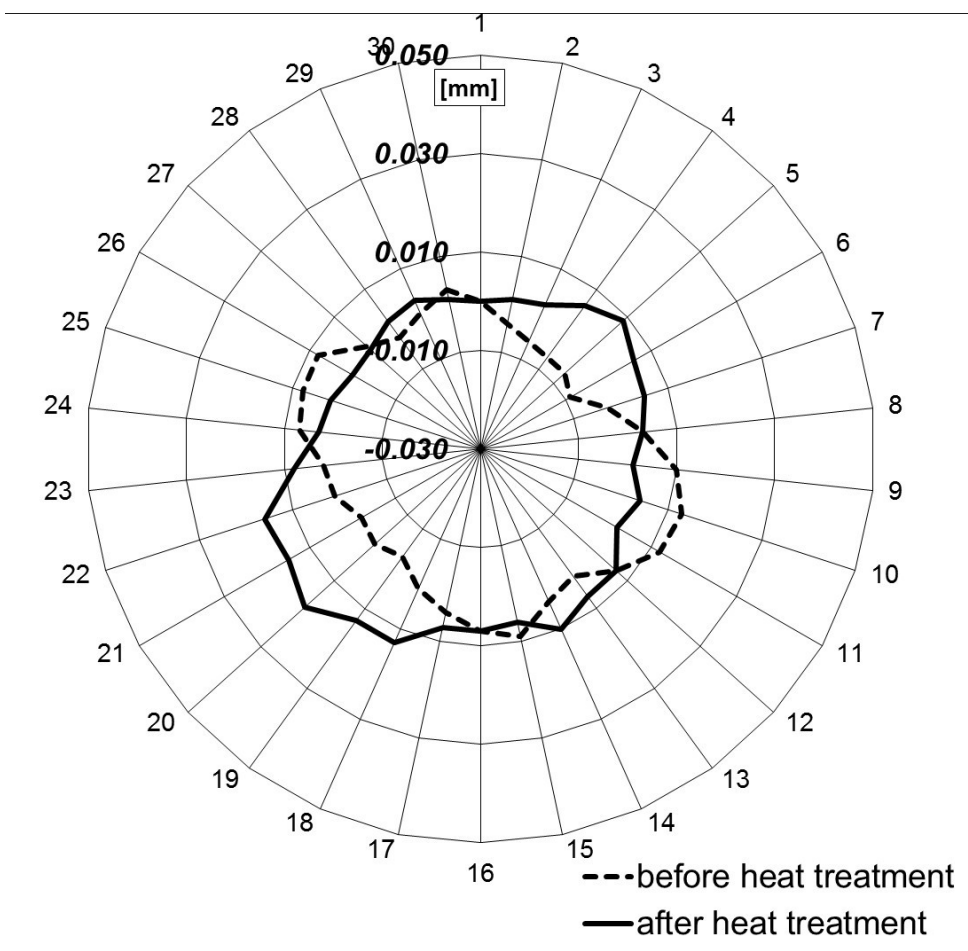

Fig. 6. Radial run-out of gear wheels made of $16 \mathrm{MnCr} 5$ steel before and after low pressure carburizing with slow cooling of the furnace 


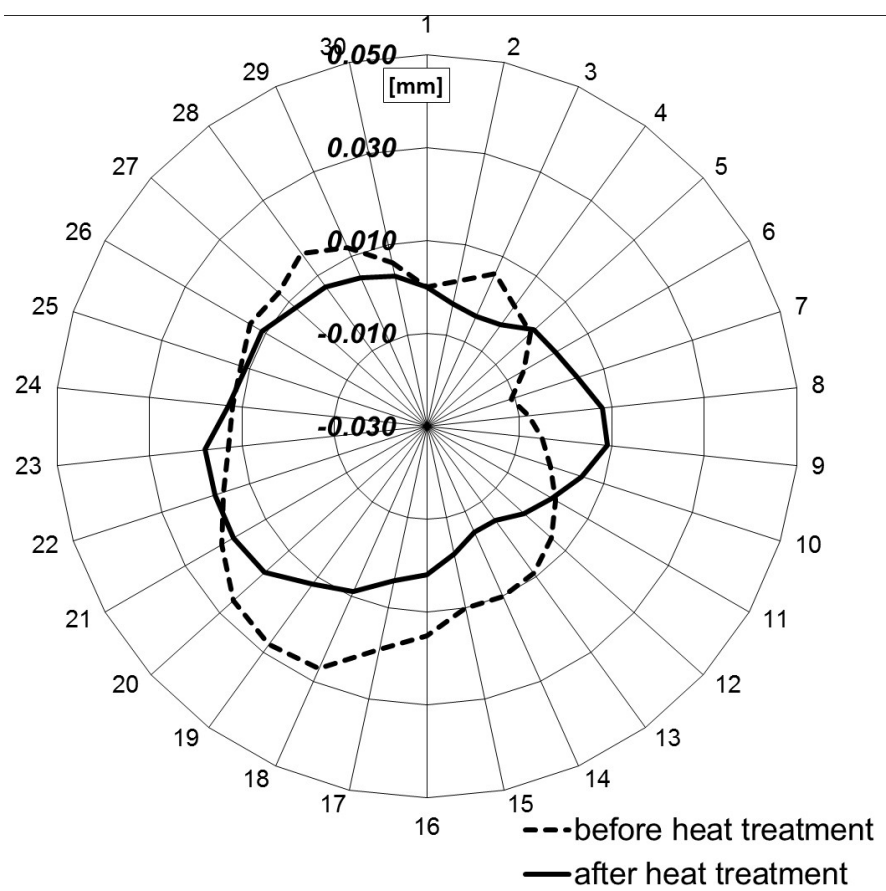

Fig. 7. Radial run-out of gear wheels made of $16 \mathrm{MnCr} 5$ steel before and after low pressure carburizing with gas hardening

average size of the deformation the thickness of the teeth for the gear wheels after gas quenching and slow cooling of the furnace presented in Table 2.

An assessment of the distortion of gearwheels was based on the measurements of radial run-outs and the diversity in notch thickness. There was a slight increase in the average value of the radial run-out measured on the pitch diameter after carburizing and gas quenching compared to the carburizing only without any

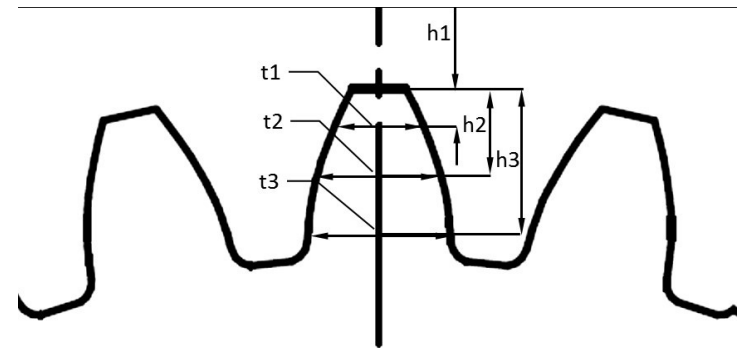

Fig. 8. Places of the thickness measurement of the teeth [3]

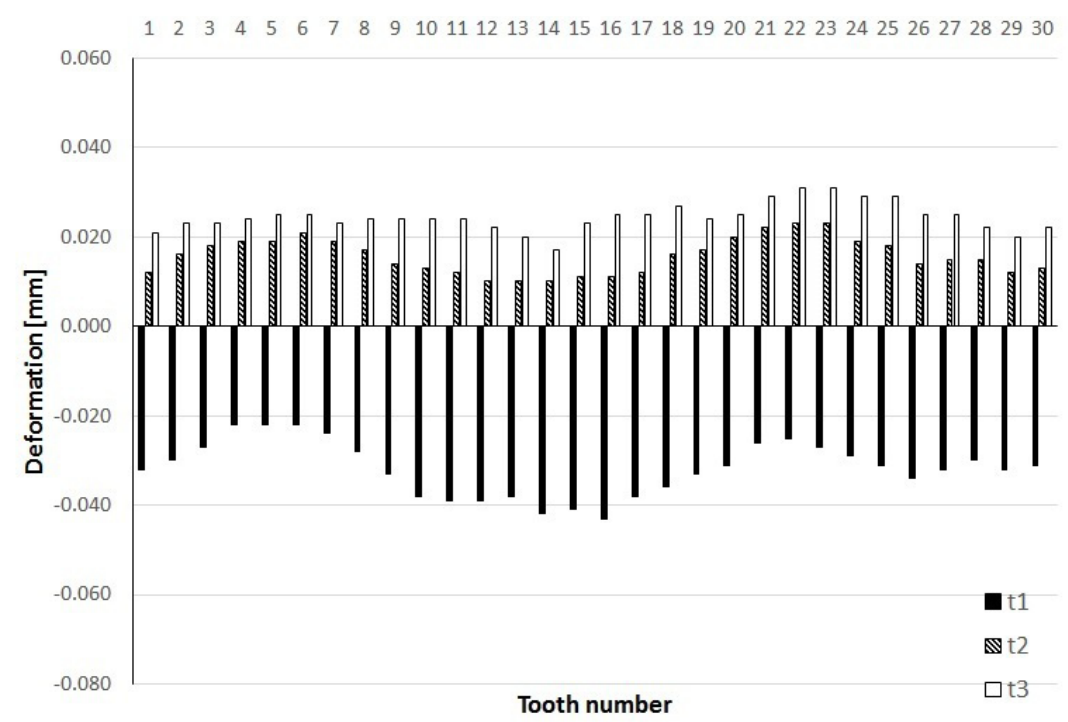

Fig. 9. Deformation of gear teeth made of $16 \mathrm{MnCr} 5$ steel after low pressure carburizing with slow cooling of the furnace 


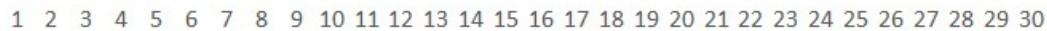

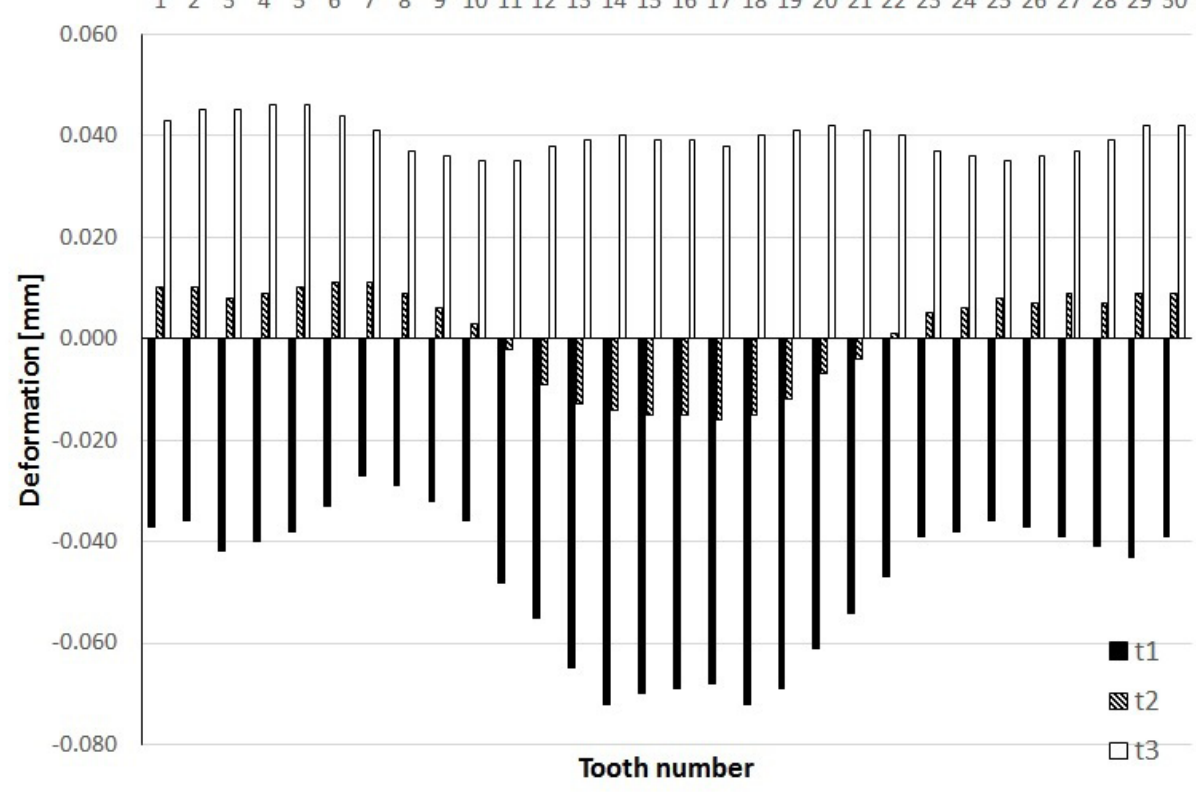

Fig. 10. Deformation of gear teeth made of $16 \mathrm{MnCr} 5$ steel after low pressure carburizing with gas hardening

Table 2. The average size of the deformation the thickness of the teeth for the gear wheels after gas quenching and slow cooling of the furnace

\begin{tabular}{|c|c|c|c|}
\hline \multirow{2}{*}{ Quenching method } & \multicolumn{3}{|c|}{ Tooth thickness [mm] } \\
\cline { 2 - 4 } & $\mathrm{t}_{1}$ & $\mathrm{t}_{2}$ & $\mathrm{t}_{3}$ \\
\hline Gas & $-0,047 \pm 0,014$ & $0,001 \pm 0,010$ & $0,040 \pm 0,003$ \\
\hline Slow cooling of the furnace & $-0,032 \pm 0,006$ & $0,016 \pm 0,004$ & $0,024 \pm 0,003$ \\
\hline
\end{tabular}

quenching. However, the distortion is more uniform after carburizing only than after the accompanied quenching in gas.

The distortion volume estimated on the thickness range of the gearwheel is more considerable. After carburizing and quenching, the increase in distortion of the thickness of the tooth was clearly visible, which was not the case after carburizing only. The average distortion between the head and foot of the tooth was approximately $0.070 \mathrm{~mm}$ to $0.120 \mathrm{~mm}$. After carburizing only, this figure was approximately 0.045 to $0.065 \mathrm{~mm}$.

\section{CONCLUSIONS}

Based on the research presented, the following conclusions can be drawn:

1. High pressure gas quenching after carburizing causes an increase in the distortion of average-sized tooth in gearwheels made of the $16 \mathrm{MnCr} 5$ steel of about $50-70 \%$.

2. As a result of quenching, the distortion of the evolvent increases, which makes the correction of tooth sizes more difficult.
3. After quenching in gas, the character and repeatability of deformation on the wheel circumference is intact, therefore making it is easier to predict the surplus for the finishing shaping processes.

4. The distortion volume is estimated based on the radial run-out only, as with such a tooth size the full distortion volume as a result of heat treatment after carburizing is not rendered.

\section{Acknowledgements}

This study was conducted within the project INNOTECH-K1/IN1/5/159396/NCBR/12.

\section{REFERENCES}

1. Atraszkiewicz R., Januszewicz B., Kaczmarek Ł., Stachurski W., Dybowski K., Rzepkowski A. High pressure gas quenching: Distortion analysis in gears after heat treatment. Materials Science \& Engineering A, 558, 2012, 550-557.

2. Cieślik J., Kula P., Filipek S. Research on compressor utilizing hydrogen storage materials for application in heat treatment facilities. Journal of Al- 
loys and Compound, 480, 2009, 612-616.

3. Dybowski K., Sawicki J., Kula P., Januszewicz B., Atraszkiewicz R., Lipa S. The effect of the quenching method on the deformations size of gear wheels after vacuum carburizing. Arch. Metall. Mater., 61, 2B, 2016, 157-162.

4. Gawroński Z., Malasiński A., Sawicki J. Elimination of galvanic copper plating process used in hardening of conventionally carburized gear wheels. International Journal of Automotive Technology, 11, 2012, 127-131.

5. Gawroński Z., Sawicki J. Technological surface layer selection for small module pitches of gear wheels working under cyclic contact loads. Materials Science Forum, 513, 2006, 69-74.

6. Gräfen W., Edenhofer B. New developments in thermo-chemical diffusion processes. Surface \& Coatings Technology, 200, 2005, 1830-1836.

7. Gräfen W., Hornung M., Irretier O., Rink M. Applications of low-pressure carburizing with high temperatures $\left(1000^{\circ} \mathrm{C}\right.$ to $\left.1050^{\circ} \mathrm{C}\right)$ in industrial practice. Haerterei-Technische Mitteilungen, 62(3), 2007, 97-102.

8. Herring D.H., Houghton R.L. The influence of process variables on vacuum carburizing. Proc. of the Sec. Intern. Conf. Carburizing and Nitriding with Atmospheres, Cleveland, USA, 1995, 103-108.

9. Hoffmann F.T., Lübben T., Mayr P. Innovations in quenching systems and equipment: current status and future developments. Heat Treatment of Met- als, 3, 1999, 63-67.

10. Jurči P., Stolař P. Distortion behaviour of gear parts due to carburizing and quenching with different quenching media. BHM Berg- und Hüttenmännische Monatshefte, 151(11), 2006, 437-441.

11. Kula P., Dybowski K., Wolowiec E., Pietrasik R. "Boost-diffusion" vacuum carburising - process optimisation. Vacuum, 99, 2014 175-179.

12. Kula P. , Kaczmarek Ł., Dybowski K., Pietrasik R., Krasowski M. Activation of carbon deposit in the process of vacuum carburizing with preliminary nitriding, Vacuum, 87, 2013, 26-29.

13. Kula P., Pietrasik R., Dybowski K., Pawęta S., Wołowiec E. Properties of surface layers processed by a new, high-temperature vacuum carburizing technology with prenitriding - PreNitLPC®., Advanced Materials Research, 452-453, 2012, 401-406.

14. Kula P., Olejnik J., Heilman P. European Patent No.: EP1558780, 2007, United States Patent No.: US 7513958, 2009.

15. Loeser K., Heuer V., Faron D. R. Distortion control by innovative heat treating technologies in the automotive industry. HTM Härtereitechnische Mitteilungen, 61(6), 2006, 326-329.

16. Preisser F., Seemann G., Zenker W.R. Vacuum carburizing with high pressure gas quenching - the application. Proc. of The 1st International Automotive Heat Treating Conference, Puerto Vallarta, Mexico, 1998, 135-147. 